\title{
Activation of the catalytic core of a group I intron by a remote 3' splice junction
}

\author{
François Michel, ${ }^{1}$ Luc Jaeger, ${ }^{1,2}$ Eric Westhof, ${ }^{2}$ Richard Kuras, ${ }^{1,4}$ Frédérique Tihy, ${ }^{1,5}$ Ming-Qun Xu, ${ }^{3}$ \\ and David A. Shub ${ }^{3}$ \\ ${ }^{1}$ Centre de Génétique Moléculaire du Centre National de la Recherche Scientifique (CNRS), Laboratoire Associè à \\ l'Université Pierre et Marie Curie, 91198 Gif-sur-Yvette Cedex, France; ${ }^{2}$ Institut de Biologie Moléculaire et Cellulaire du \\ CNRS, 67084 Strasbourg-Cedex, France; ${ }^{3}$ Department of Biological Sciences and Center for Molecular Genetics, University \\ of New York at Albany, Albany, New York 12222 USA
}

\begin{abstract}
Over 1000 nucleotides may separate the ribozyme core of some group I introns from their $3^{\prime}$ splice junctions. Using the sun $Y$ intron of bacteriophage $T 4$ as a model system, we have investigated the mechanisms by which proximal splicing events are suppressed in vitro, as well as in vivo. Exon ligation as well as cleavage at the $5^{\prime}$ splice site are shown to require long-range pairing between one of the peripheral components of the ribozyme core and some of the nucleotides preceding the authentic $3^{\prime}$ splice junction. Consistent with our three-dimensional modeling of the entire sun $Y$ ribozyme, we propose that this novel interaction is necessary to drive $5^{\prime}$ exon-core transcripts into an active conformation. A requirement for additional stabilizing interactions, either RNA-based or mediated by proteins, appears to be a general feature of group I self-splicing. $A$ role for these interactions in mediating putative alternative splicing events is discussed.
\end{abstract}

[Key Words: Group I intron; maturase; ribozyme activation; RNA-RNA interaction; self-splicing; sunY intron]

Received January 13, 1992; revised version accepted May 20, 1992.

All group I introns share a common core that is endowed with ribozyme activity and consists of six to eight basepaired segments (P2-P9) connected by conserved nucleotides (for review, see Cech 1988, 1990). At the same time, all known group I introns include additional, noncore stretches of sequence, which can include from a few dozen to several thousand nucleotides [see the latest compilation by Michel and Westhof (1990)]. Many of those inserts interrupt core sequences, but some of them separate the core from either the $5^{\prime}$ or $3^{\prime}$ splice site. The latter type of organization raises the obvious possibility of alternative splicing, first invoked by Hensgens et al. (1983) for one of the group I introns in yeast mitochondria.

That alternative splicing mediated by the core of a group I intron is not a purely theoretical view can be illustrated by the sun $Y$ intron of bacteriophage $\mathrm{T} 4$, whose ribozyme core and 3 ' extremity are separated by a 777-nucleotide reading frame (Shub et al. 1988). Incubation of truncated sun $Y$ transcripts under optimal in vitro splicing conditions results in multiple splicing events, owing to the use of a number of surrogate 3 ' splice sites in the first $\sim 50$ nucleotides downstream of the core

Present addresses: ${ }^{4}$ Institut de Biologie Physico-Chimique, 75005 Paris, France; ${ }^{5}$ Département de Pathologie de l'Université de Montreal, 6128 sucA Montreal, Canada H3C $3 J 7$.
(Michel et al. 1990). As is the rule in group I, all efficient splicing events occur immediately $3^{\prime}$ of a G residue: The terminal $G$ of group I introns is believed to replace the free guanosine cofactor in the guanosine-binding site once cleavage at the $5^{\prime}$ splice site has occurred (Inoue et al. 1986; Michel et al. 1989; Been and Perrotta 1991). In addition, the nucleotides immediately preceding and following a selected $G$ have been shown to participate in the selection process through formation of two basepaired segments called P9.0 and P10 (see Fig. 4, below). Formation of the P9.0 pairing (Burke 1989; Michel et al. 1989, 1990; Burke et al. 1990) brings the terminal G in close proximity to helix P7 and the guanosine-binding site. Formation of P10 (initially proposed by Davies et al. 1982) brings the phosphodiester bond between the terminal $\mathrm{G}$ and $3^{\prime}$ exon next to the $3^{\prime} \mathrm{OH}$ attacking group of the 5' exon (Michel et al. 1989; Partono and Lewin 1990; Suh and Waring 1990). Judging from our experience with the sunY system, however, only minimal pairing to the $5^{\prime}$ strands of P9.0 and/or P10 is required of a surrogate $3^{\prime}$ splice sequence (Michel et al. 1990).

Assuming that truncated transcripts are reasonable substitutes for the products of ongoing transcription, one would conclude that alternative splicing might be biologically relevant in the case of sun $Y$ and similarly organized group I introns. Nevertheless, we were unable to detect proximal splicing of the sun $Y$ intron, either in 
vivo or (when using full-length transcripts) in vitro. This suggested that additional mechanisms might be involved in ensuring the correct choice of a 3' splice junction. We now report base-pairing between one of the peripheral components of the ribozyme core and some of the nucleotides preceding the authentic $3^{\prime}$ splice site. This additional interaction is necessary for the formation of fully active sunY transcripts, both in vivo and under low magnesium conditions in vitro, which readily explains how proximal splicing events are suppressed.

\section{Results}

\section{Splicing of truncated sunY transcripts requires elevated magnesium concentrations}

Although all self-splicing group I introns require magnesium for activity, the critical threshold of magnesium concentration at which the molecules become reactive differs from one intron to the next. In the case of the sunY intron, we observed complete precursor transcripts to become active between 2 and $3 \mathrm{mM} \mathrm{MgCl}$ (data not shown), but truncated transcripts require significantly higher magnesium concentrations, because no activity (i.e., cleavage at the intron-5'-exon junction) is observed below $6 \mathrm{mM} \mathrm{MgCl}_{2}$ (Fig. 1).

Presence of the proximal splice sites at positions 238 and 243 (Fig. 1, Michel et al. 1990) is not sufficient to alleviate this elevated magnesium requirement, for tran- scripts truncated at the DraI site, 135 nucleotides from the $3^{\prime}$ end of the P9 stem-and-loop structure (the last, semiconserved core component), fare no better than those truncated just next to it, at the PvuII site (Fig. 1). On the other hand, because most of the intervening sequence between the core and $3^{\prime}$ splice junction appears to be looped out by the P9.1 pairing (whose existence is supported by comparative analysis of the three known bacteriophage T4 introns; Shub et al. 1988; see also Fig. 4, below), we tested whether the P9.1 terminal loop could be shortened: SYCl transcripts, which lack 712 of 742 nucleotides in that loop, have the same low magnesium requirement as complete sun $Y$ transcripts. Finally, adding some of the nucleotides surrounding the authentic $3^{\prime}$ splice junction back to a truncated construct has no effect. Although the SYK15 precursor RNA undergoes an efficient splicing reaction leading to normally ligated exons when active, it still shows the same dependence on magnesium as a molecule truncated at the PvuII site immediately after P9 (Fig. 1). It can therefore be concluded that the critical elements, whose absence is responsible for the elevated magnesium requirement of truncated transcripts, are the P9.1 and/or P9.2 stem-andloop structures.

Additional information was obtained from a series of Bal 31-induced deletions encompassing the P9.1 and P9.2 segments. The pMEE1 DNA in which these deletions were introduced possesses a further shortened P9.1 stem-and-loop structure compared with $\mathrm{pSYCl}$; but RNA transcribed from it is still active at $3 \mathrm{mM} \mathrm{MgCl}_{2}$,
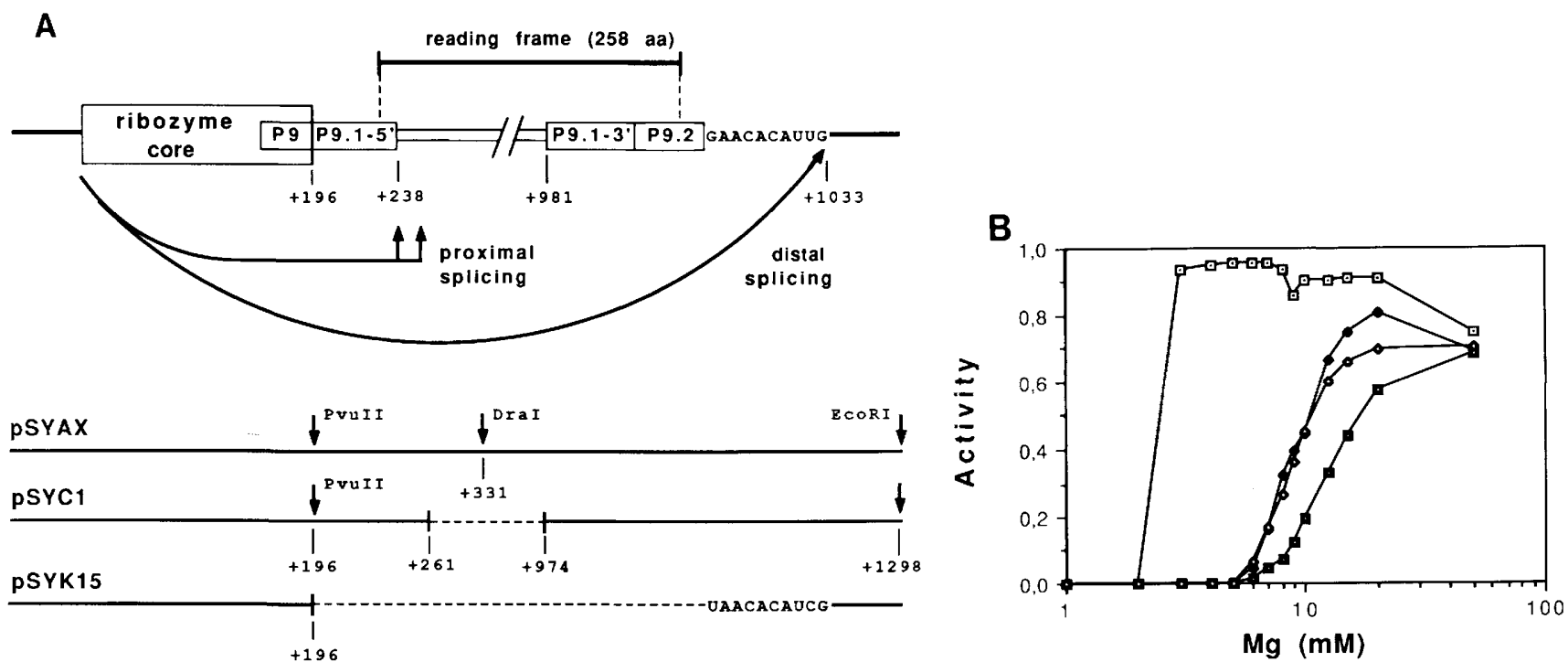

Figure 1. Dependence of the in vitro activity of complete and truncated forms of the sun $Y$ intron on magnesium concentration. $|A|$ The functional organization of the sunY intron is shown at top. Exon sequences are symbolized as solid lines, and intron components as open boxes. P9, P9.1-5', P9.1-3', and P9.2 are predicted secondary structure components (see Fig. 4). Maps of pSYAX-, pSYC1-, and pSYK15-derived transcripts are shown at bottom (see also Materials and methods); PvuII, DraI, and EcoRI are truncation sites for runoff transcription. $(B)$ In vitro activity of complete and truncated transcripts of the sunY intron as a function of magnesium concentration. The fraction of precursor RNA molecules cleaved at the intron- $5^{\prime}$ exon junction after 5 min reaction at $37^{\circ} \mathrm{C}$ is plotted vs. the $\log$ of $\mathrm{MgCl}_{2}$ concentration. (Dotted open squares) Precursor RNA generated from EcoRI-digested pSYC1 DNA; (solid diamonds) RNA from PvuII-digested pSYC1 DNA; (dotted solid squares) RNA from DraI-digested pSYAX DNA; (open diamonds) RNA from EcoRI-digested pSYK15 DNA. 
although the rate of splicing is slightly reduced. When characterized for their ability to splice in transcription buffer ( $8 \mathrm{mM} \mathrm{MgCl}_{2}, 1.2 \mathrm{~mm}$ total dNTP), the RNAs generated from deletion derivatives of pMEE1 DNA proved extremely diverse (Fig. 2). However, the essential result is that none of the RNAs lacking the terminal base pairs and/or loop nucleotides of P9.2 spliced efficiently under those conditions, whereas most of the molecules with an intact P9.2 did so.

\section{Presence of the P9.2 stem and loop is essential for bimolecular recognition of the authentic splice junction by the ribozyme core}

To facilitate identification of the structural components involved in mutual recognition of the 3 ' splice junction and ribozyme core, we set up bimolecular reactions in which transcripts truncated $3^{\prime}$ of the core were incubated with molecules carrying some of the sequences surrounding the $3^{\prime}$ splice junction [for convenience, a $\mathrm{ClaI}$ site was introduced at the $3^{\prime}$ junction, by changing the penultimate intron nucleotide to $\mathrm{C}$, and the P9.0 pairing was restored by changing intron position 177 to G (see Fig. 4, below); resulting full-length and truncated transcripts behave essentially as their wild-type counterparts, except for their choice of proximal splice sites (Michel et al. 1990 and data not shown).] As shown in Figure 3B, the S2 RNA, which retains 61 nucleotides upstream of the 3' splice site and 66 nucleotides downstream of it, does react with a Dral-truncated 5 '-exoncore transcript, even if incompletely so (cf. with control lanes). The three products observed have the expected lengths for spliced exons on the one hand, and molecules resulting from hydrolysis at the normal 3 ' splice junction on the other. Also, trans-splicing involving the S2 RNA is seen to efficiently inhibit proximal splicing of the DraI-truncated transcript, as shown from the absence of the ligated exon and linear intron forms normally resulting from incubation of that transcript under splicing conditions. The latter effect can be used to estimate the affinity of the distal 3 ' splice junction for the ribozyme core. As seen in Figure 3D, the critical concentration resulting in $50 \%$ inhibition of proximal splicing in our experimental setting is $\sim 10 \mathrm{~nm}$.
We then proceeded to determine which structural components were essential for this trans-splicing reaction. One likely candidate for pulling together the core and $3^{\prime}$ end of the sunY intron was the P9.1 pairing, whose P9.1a and P9.1c substems should total no less than 17 bp according to current secondary structure models of the intron (Shub et al. 1988; Fig. 4). Rather surprisingly, the P9.1 pairing proved dispensable in trans-splicing, because a $5^{\prime}$ exon-core transcript truncated at the PvuII site (and therefore lacking the $5^{\prime}$ strands of the P9.1 pairings) still recognizes and cleaves a $3^{\prime}$ splice site RNA (Fig. 3C). The P10 pairing is neither absolutely necessary nor (in conjunction with P9.0) sufficient to ensure bimolecular splicing, for (1) the S3 RNA, whose $3^{\prime}$ exon sequence is unrelated to that of sunY except for the first $\mathrm{A}$, still undergoes trans-splicing, although with a somewhat reduced efficiency (as judged from the fact that inhibition of proximal splicing is not complete); and (2) the S4 RNA, which has a wild-type $3^{\prime}$ exon sequence, but only 2 nucleotides (the ones that constitute the $3^{\prime}$ strand of P9.0) remaining upstream of the $3^{\prime}$ splice site, is not recognized. Finally, adding back the nucleotides of the wild-type sequence up to the $3^{\prime}$ end of the P9.2 pairing has no effect, as judged from the fact that the K15 RNA is still not recognized. In summary, these experiments point to P9.2 being a key element in promoting bimolecular splicing of $5^{\prime}$ exon-core and $3^{\prime}$ splice site transcripts.

\section{Base-pairing between the 7.2 and 9.2 terminal loops is required for correct folding of the sunY intron at low magnesium concentrations}

While only core components are (by definition) common to all group I introns, subgroups can nevertheless be distinguished based on possession of shared peripheral structures (Michel et al. 1982; Cech 1988; Michel and Westhof 1990). Thus, all three known bacteriophage T4 introns have four extra P7 and P9 stem-and-loop structures, each of which is related to its counterparts in the other two introns (Shub et al. 1988; Fig. 4). This is particularly clear in the case of P7.2 and P9.2, as the sequences of the L7.2 and L9.2 terminal loops (and also the P7.2 stem) are highly conserved in the three T4 introns.

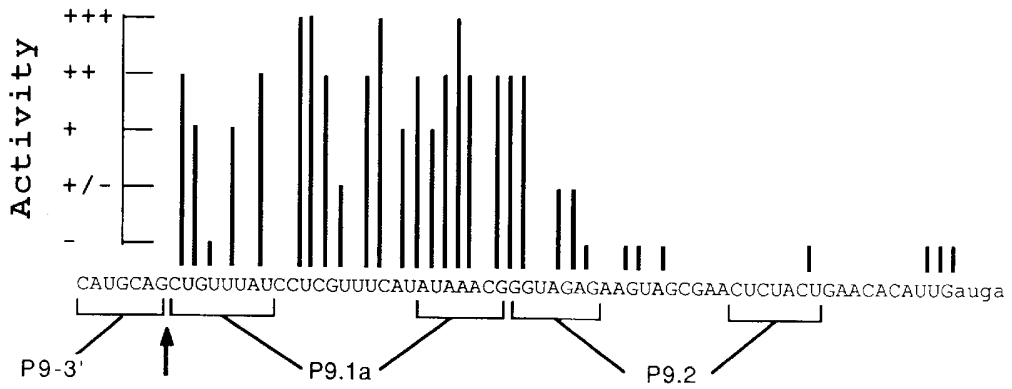

Figure 2. Deletion analysis of the role played by the $3^{\prime}$ part of the sunY intron in determining splicing activity. The sequence is that of the intron- $3^{\prime}$ exon junction of pMEE1-derived RNA $13^{\prime}$ exon nucleotides are in lowercase). P9-3', P9.1 a, and P9.2 are predicted secondary structure components (see Fig. 4). The left end point of the Bal 31 deletions introduced in pMEEl (see Materials and methods) is marked by a vertical arrow. The right end points of the deletions are indicated by vertical bars, whose heights match the observed splicing activity of corresponding RNAs during in vitro transcription [activity was estimated relative to pMEE1 RNA and scored as high $(+++)$, moderate $(++)$, low $1+1$, poor $(+/-)$ or nil $(-)]$. 


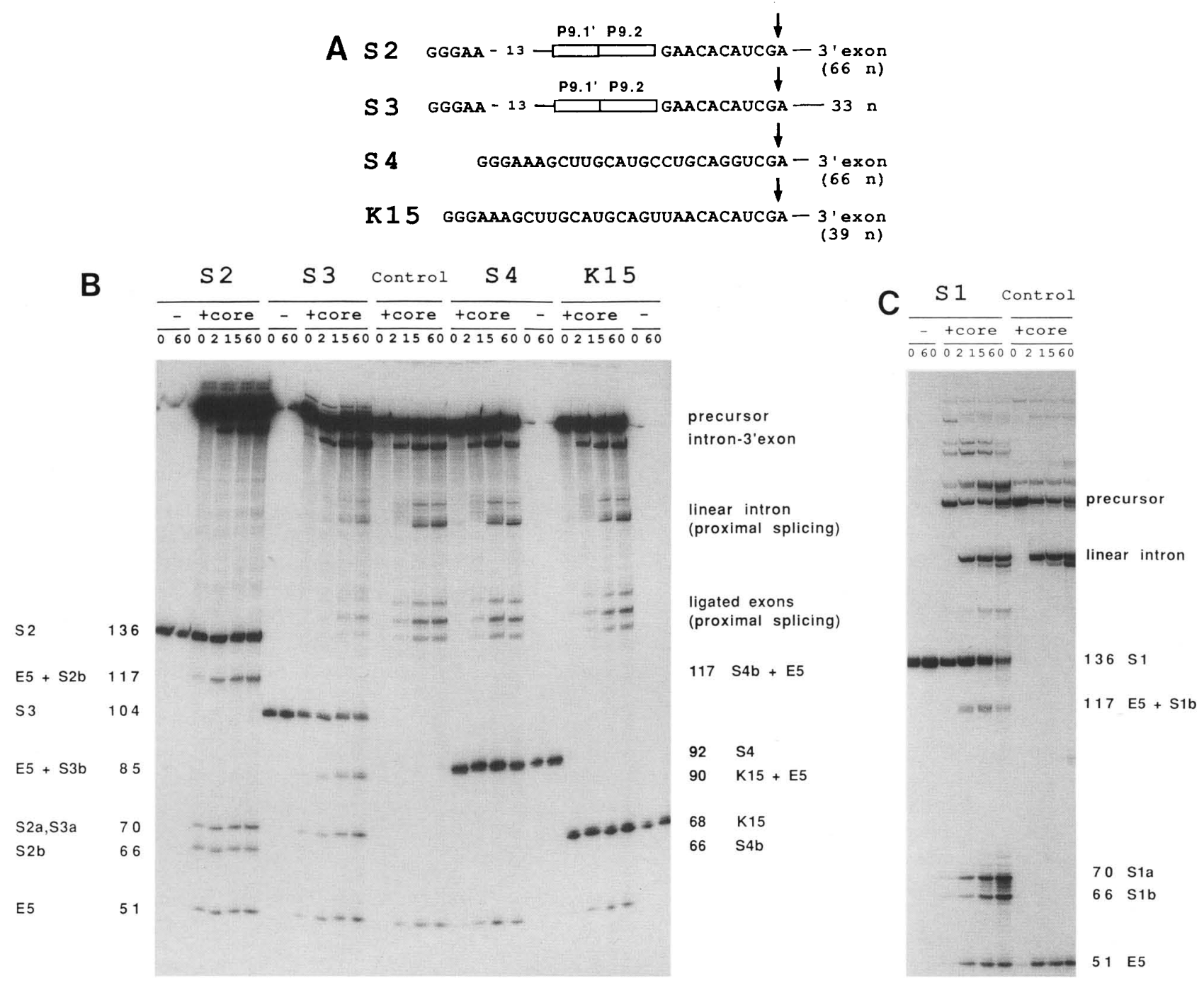

Figure 3. Bimolecular splicing of $5^{\prime}$ exon-core molecules with transcripts including 3 '-terminal components of the sunY intron. (A) Structure of transcripts used in trans-splicing experiments with $5^{\prime}$ exon-core RNA. Transcripts were generated from EcoRI digests of the corresponding DNAs (for construction of the DNA templates, see Materials and methods). P9.1-3' and P9.2 are predicted secondary structure components of the sunY intron. The vertical arrow points to the expected 3 ' splice junction (except for the $\mathrm{S} 3$ transcript, the sequence to the right of the arrow matches that of the sunY $3^{\prime}$ exon). $(B)$ Trans-splicing experiments. Gel-purified, ${ }^{32} \mathrm{P}$-labeled RNAs (final concentration, $0.1 \mu \mathrm{M}$ ) whose sequences are shown in $A$ were separately incubated with a gel-purified, ${ }^{32} \mathrm{P}$-labeled truncated sunY transcript (final concentration, $0.1 \mu \mathrm{M}$ ), generated from DraI-digested pTZ19U/T4AS/177G;210G;216C DNA (see Materials and methods). Splicing conditions: $45^{\circ} \mathrm{C}, 50 \mathrm{~mm}$ Tris- $\mathrm{Cl}$ at $\mathrm{pH} 7.5\left(25^{\circ} \mathrm{C}\right), 50 \mathrm{~mm} \mathrm{NH}{ }_{4} \mathrm{Cl}, 30 \mathrm{~mm} \mathrm{MgCl}$, $0.02 \%$ SDS. Reactions were started by the addition of GTP to a final concentration of $1 \mathrm{~mm}$. Aliquots were mixed at $0,2,15$, and $60 \mathrm{~min}$ with an equal volume of loading buffer and $\mathrm{Na}_{2}$-EDTA to a final concentration of $40 \mathrm{~mm}$ prior to loading on a $5 \%$ acrylamide- $8 \mathrm{M}$ urea gel. Each experiment included a control sample without core RNA (0 and 60 min lanes). Expected products and their sizes are indicated (S2a, S3a, S2b, S3b, and S4b) designate sections of S2, S3, and S4 RNAs lying at the left and right sides, respectively, of the expected splice

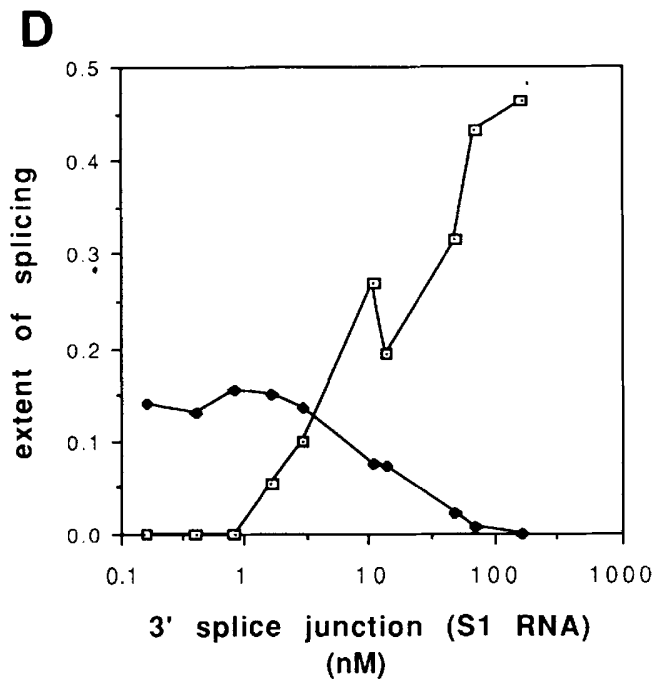
site; E5 is the $5^{\prime}$ exon; sequence ladders were used for size calibration!. (C) Bimolecular splicing in the absence of a P9.1 pairing. Gel-purified ${ }^{32}$ P-labeled S1 RNA (final concentration, $0.1 \mu \mathrm{M}$ ), generated from EcoRI-digested pSS1 DNA (see Materials and methods), was incubated with a gel-purified, ${ }^{32} \mathrm{P}$-labeled sunY core transcript (final concentration, $0.1 \mu \mathrm{M}$ ) generated from $P_{V u I I-d i g e s t e d ~ p S Y C 1}$ DNA. Experimental procedures are as in $B .(D)$ Inhibition of proximal splicing by an RNA molecule carrying the distal splice junction. Various amounts of S1 RNA were mixed with a truncated sunY transcript (final concentration $2.4 \mathrm{nM}$ ) generated from DraI-digested pSYAX DNA. Experimental conditions are as in B. Samples were incubated for 60 min under reaction conditions prior to loading on a $5 \%$ acrylamide $-8 \mathrm{~m}$ urea gel. (Solid diamonds) Fraction of precursor molecules having undergone proximal splicing after $60 \mathrm{~min}$ (as determined from amount of excised intron forms); (dotted open squares) fraction of precursor molecules having undergone bimolecular splicing (as determined from amount of E5/S1b-ligated exons). 


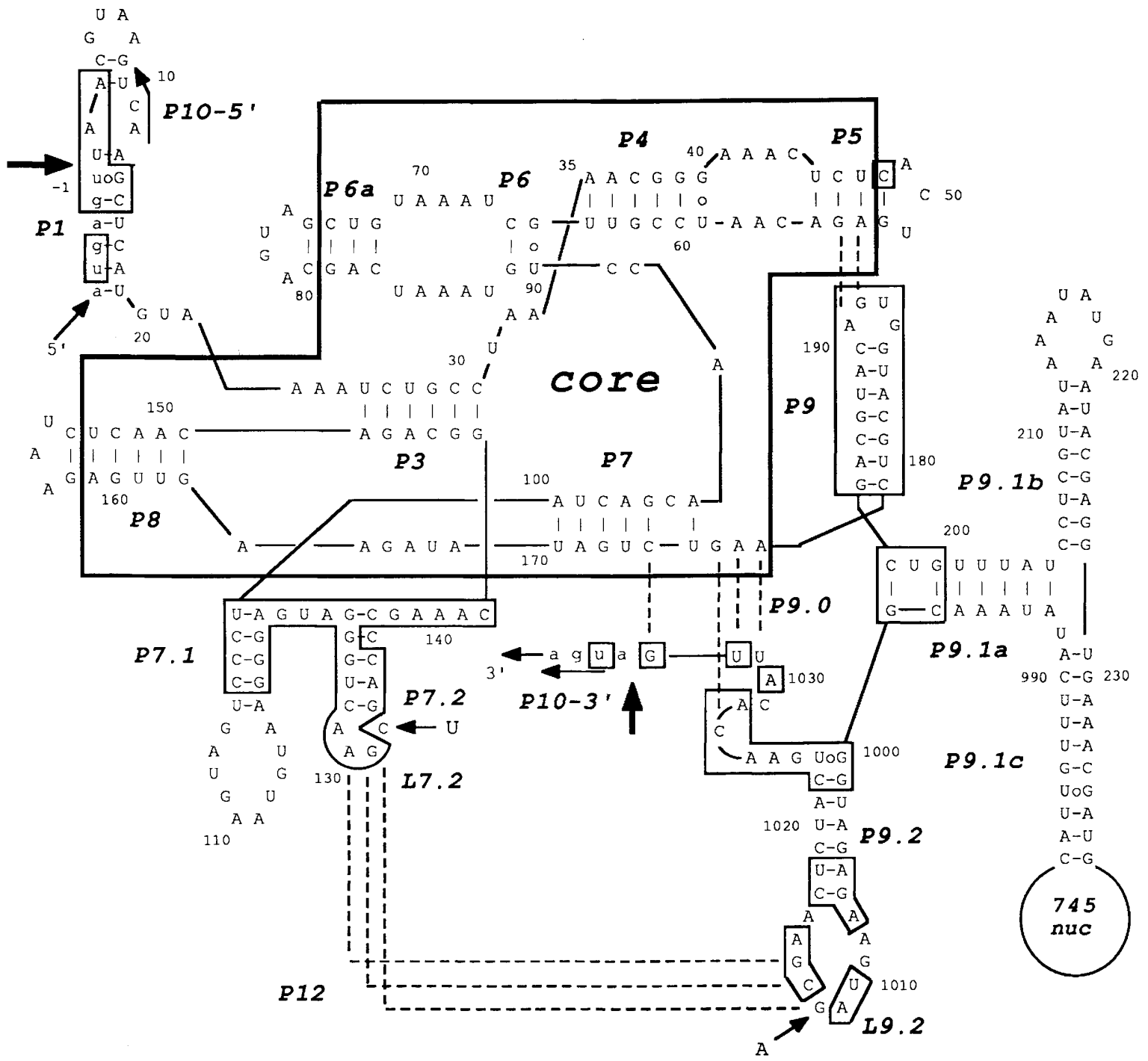

Figure 4. Secondary structure model of the sunY intron (Shub et al. 1988), drawn according to Michel and Westhof (1990). (P1-P10) Base-paired segments. Heavy arrows point to splice junctions (exons are in lowercase). The ribozyme core common to all group I introns is enclosed by a heavy line. Base-pairings involving noncore components are indicated by broken lines. Boxed noncore sections are conserved in the $t d$ intron of bacteriophage T4 (Shub et al. 1988; note the compensatory base changes in the L7.2 and L9.2 terminal loops). The model conforms to the secondary structure proposed by Shub et al. (1988), except that P9.1 was remodeled to accommodate a bulge on its $5^{\prime}$ side to maximize similarity to the other two bacteriophage T4 introns.

In the light of this observation, and also the fact that removal of the P7.1-P7.2 insert results in an intron that is inactive, except at high magnesium concentrations (Doudna and Szostak 1989), we decided to investigate the possible role of $\mathrm{P} 9.2$, as well as $\mathrm{P} 7.2$, in ensuring low magnesium requirements for splicing.

In a first step, 2 consecutive nucleotides were substituted in the L7.2 and L9.2 loops of pSYC3, resulting in (untrucated) mutant precursor RNAs G131C; $\mathrm{Cl} 32 \mathrm{G}$ and G1012C;C1013G, respectively. Although these RNAs proved to be affected little, if at all, at $30 \mathrm{~mm} \mathrm{MgCl}_{2}$ and $45^{\circ} \mathrm{C}$ (Fig. $5 \mathrm{a}$ ), the L 7.2-substituted molecule proved to be largely inactive at $5 \mathrm{mM} \mathrm{MgCl}_{2}$, and $30^{\circ} \mathrm{C}$ (Fig. $5 \mathrm{~b}$ ). Also, for the L9.2 mutant, conversion of precursor RNA into products was found to reach a plateau, at typically $\sim 50 \%$ in our standard experimental conditions (cf. with unsubstituted molecules, which reacted up to $\sim 85 \%$ ).

One possible interpretation of these results was that our renaturation protocol (see Materials and methods) did not allow all of the L9.2-substituted molecules (that had been gel purified and denatured at $80^{\circ} \mathrm{C}$ in water) to regain activity at $5 \mathrm{mM} \mathrm{MgCl}_{2}$ and $30^{\circ} \mathrm{C}$. Varying the way the samples were renatured was found to result in strikingly different extents of reactivity, not only for L9.2substituted RNA but also for the L7.2- and nonsubstituted (wild-type) samples (Fig. 5c). For instance, addition of concentrated splicing buffer during quick cooling from $80^{\circ} \mathrm{C}$ resulted in very poor renaturation, even of the wild- 

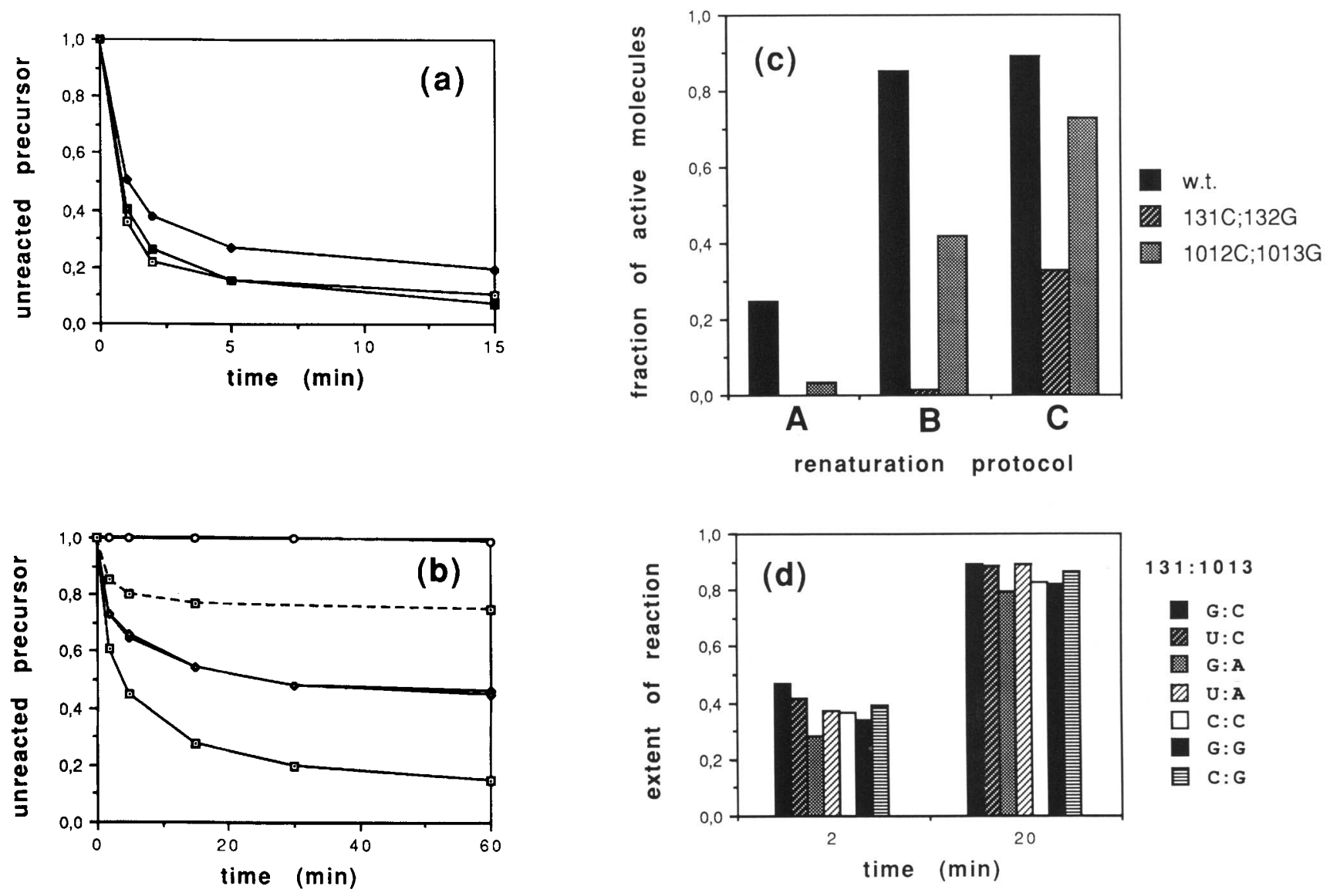

Figure 5. The reactivity of complete sunY transcripts is affected by both nucleotide substitutions in the L7.2 and L9.2 terminal loops and renaturation protocols. $a$ and $d$ are time courses of the conversion of precursor RNAs into splicing products. $(a)$ High magnesium conditions. RNA samples were denatured by heating at $80^{\circ} \mathrm{C}$ in water and cooled quickly to $45^{\circ} \mathrm{C}$ before the addition of 0.25 volume of concentrated $(5 \times)$ splicing buffer [final concentrations, $50 \mathrm{~mm}$ Tris- $\mathrm{Cl}$ at $\mathrm{pH} 7.5\left(25^{\circ} \mathrm{C}\right), 50 \mathrm{mM} \mathrm{NH}_{4} \mathrm{Cl}_{2} 0.02 \% \mathrm{SDS}, 30 \mathrm{mM} \mathrm{MgCl}$ ]. Reaction was started by the addition of GTP to a final concentration of $1 \mathrm{mM}$. (Dotted open squares) RNA from EcoRI-digested pSYC3 DNA; (solid diamonds) RNA from G131C;C132G pSYC3 derivative; (dotted solid squares) RNA from G1012C;Cl013G pSYC3 derivative. (b) Low magnesium conditions. (Solid curves) The same as $a$, except that after addition of $5 \times$ splicing buffer (final $\mathrm{MgCl}_{2}$ concentration, $5 \mathrm{~mm}$ ), samples were cooled slowly $\left(-0.8^{\circ} \mathrm{C} / \mathrm{min}\right.$ ) to $30^{\circ} \mathrm{C}$ before the addition of GTP. (Dotted open squares) SYC3 RNA; (open circles) SYC3 G131C;C132G RNA; (open diamonds) and (solid diamonds) SYC3 G1012C;C1013G RNA (replicate experiments). (Dashed curve) After heating at $90^{\circ} \mathrm{C}$ in water, the sample was removed from the bath, $5 \times$ splicing buffer (final $\mathrm{MgCl}_{2}$ concentration $5 \mathrm{mM}$ ) was added quickly, and the sample was transferred directly to $30^{\circ} \mathrm{C}$ before the addition of GTP. RNA was from EcoRI-digested pSYC3 DNA. (c) Effects of renaturation protocols on the reactivity of wild-type and substituted SYC3 RNAs. Reaction conditions are as in $b$. All samples were initially denatured at $90^{\circ} \mathrm{C}$ in water. (Protocol $A$ ) Samples were removed from the bath, low $\mathrm{MgCl}_{2}, 5 \times$ splicing buffer was added, and the samples were transferred to $30^{\circ} \mathrm{C}$ in quick succession. (Protocol $B$ ) Samples were cooled quickly to $45^{\circ} \mathrm{C}$, low $\mathrm{MgCl}_{2}, 5 \times$ splicing buffer was added, and the samples were cooled slowly $\left(-0.8^{\circ} \mathrm{C} / \mathrm{min}\right)$ to $30^{\circ} \mathrm{C}$. (Protocol $\left.\mathrm{C}\right)$ Samples were cooled quickly to $45^{\circ} \mathrm{C}$, high magnesium (final $\mathrm{MgCl}_{2}$ concentration $30 \mathrm{~mm}$ ) $5 \times$ splicing buffer was added, and the samples were incubated for $5 \mathrm{~min}$ before the dilution to $5 \mathrm{~mm} \mathrm{MgCl}$ with no $\mathrm{Mg}, 1 \times$ splicing buffer, and quick cooled to $30^{\circ} \mathrm{C}$. $(d)$ Kinetics of splicing of SYC3 RNAs variously substituted at positions 131 and 1013. Reaction conditions are as in $b$. All samples were renatured according to protocol $B$ in $c$. The fraction of active molecules, estimated from the fraction of precursor molecules that had reacted at $60 \mathrm{~min}$, varied from 0.85 (wild type, 131G;1013C) to 0.27 (131G;1013A mutant) (see Fig. 6). Ordinates correspond to the fraction of active molecules that had reacted 2 and $20 \mathrm{~min}$ after the addition of GTP at $30^{\circ} \mathrm{C}$.

type RNA. In contrast, complete renaturation at $30 \mathrm{~mm}$ $\mathrm{MgCl}_{2}$ and $45^{\circ} \mathrm{C}$, followed by dilution to $5 \mathrm{mM} \mathrm{MgCl}_{2}$ and quick cooling at $30^{\circ} \mathrm{C}$, resulted in even L7.2-substituted molecules gaining substantial activity. However, once corrected for the final plateau value, the time course of the reaction is found to depend little, if at all, on the renaturation protocol and RNA sample being used (Fig. 5b and data not shown), as would be expected if there were no interconversion of inactive and active molecules under our reaction conditions and reaction rates were unaffected by the mutations introduced in the L7.2 and L9.2 loops.

We eventually settled for a renaturation protocol ( $B$ in Fig. $5 \mathrm{c}$ ) that ensured full reproducibility of reaction data at $5 \mathrm{mM} \mathrm{MgCl}_{2}$ and $30^{\circ} \mathrm{C}$ for any given RNA /an example is shown in Fig. $5 \mathrm{~b}$ ). The stage was now set for closer 
examination of the effects of mutations in the P7.2 and P9.2 elements. Comparison of the sunY sequence with that of the closely related $t d$ intron of bacteriophage $\mathrm{T} 4$ shows that potentially compensatory base changes $(\mathrm{C} \leftrightarrow U / U \leftrightarrow C)$ and $(G \leftrightarrow A / A \leftrightarrow G)$ have occurred at positions 132 in the L7.2 loop and 1012 of the L9.2 loop, respectively. This suggested that a base-pairing (referred to as P12) might exist between nucleotides 131-132 and 1013-1012 (the sequence of the third T4 intron, $n r d \mathrm{~B}$, is also compatible with the existence of that pairing, which, in all three introns, can be extended further to positions 130 and 1014 by postulating a terminal A : G pair).

By combining the double mutations we had introduced in the L7.2 and L9.2 loops, we expected to restore the postulated L7.2-L9.2 interaction and thus prove its existence. We found (data not shown) that the resulting quadruple mutant reacts to the same extent as the L9.2 double mutant (i.e., to a much greater extent than the L7.2 double mutant, but not as well as the wild type). One possible reason for our failure to compensate the L9.2 mutation was that the L7.2 double mutation affects the structure of the L7.2 4-nucleotide loop to such an extent that the bases in that loop are no longer fully accessible for base-pairing with their partners in the L9.2 loop. Rather than attempting to test both base pairs at the same time, we therefore chose to substitute only positions 131 (originally a G) and 1013 (originally a C). The other three possible Watson-Crick base pairs at these positions were generated, and each of the resulting RNAs was compared, both to the corresponding monosubstituted variants and original, wild-type molecule. The outcome of these experiments is summarized in Figures $5 \mathrm{D}$ and 6 (note that subpopulations of active molecules were again found to react with similar kinetics, irrespective of the final plateau value reached). In each

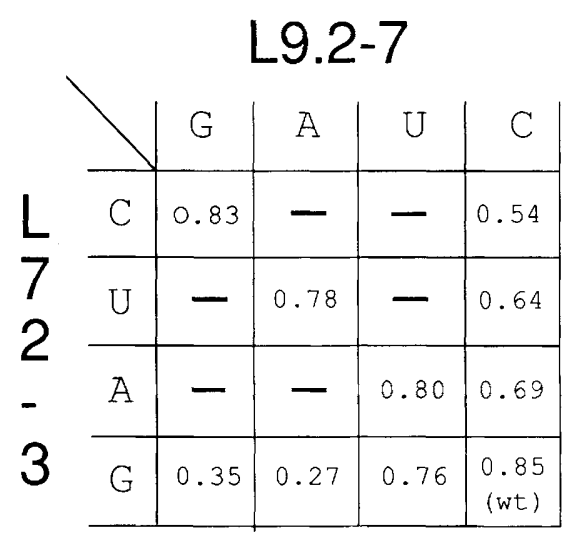

Figure 6. Compensatory effects of nucleotide substitutions at positions L7.2-3 (131) and L9.2-7 (1013). Numbers are the fraction of active molecules /estimated from the fraction of precursor molecules that had reacted $60 \mathrm{~min}$ after addition of GTP) in standard splicing buffer at $30^{\circ} \mathrm{C}$ and $5 \mathrm{mM} \mathrm{MgCl}_{2}$. RNAs were generated from EcoRI-digested pSYC3 DNA and derivatives. Gel-purified samples were renatured according to protocol B in Fig. 5c. case, matched combinations reacted to a significantly greater extent than mismatched ones, thus proving the postulated base pair. Even more remarkable, ranking of substituted RNAs on a quantitative scale according to their ability to be renatured closely matches the expected stability of base pairs within a helix, with the classic (Watson-Crick and wobble) pairs at top, followed by $\mathrm{A}: \mathrm{C}$, pyrimidine-pyrimidine mismatches and, finally, purine-purine mismatches. On the other hand, the type of classical base pair, whether $G: C, A: U$, or $G: U$, does not seem to make much difference, even though $G: C$ and $C: G$ are preferred over $A: U$ and $\mathrm{U}: \mathrm{A}$, and the latter over $\mathrm{G}: \mathrm{U}$. One possible interpretation is that only when P12 includes a mismatched base pair does its formation become the rate-limiting step for folding of the sunY intron. Alternatively, some of the molecules transcribed from wild-type DNA may not be able to self-splice at all because of structural defects, such as would result from base misincorporation during transcription or subsequent depurination; correcting our experimentally determined plateau values to account for a fraction of inert molecules would enhance the contrast between G : C, A : U, and G : U pairs. Deciding which of the two above interpretations is correct will require direct measurements of refolding rates on one hand, and a careful assessment of the quality of $\mathrm{T} 7$ polymerase transcripts on the other.

\section{In vivo effects of mutations in the 7.2 and 9.2 loops}

Because even double substitutions that completely disrupt the P12 interaction still allow substantial activity at high magnesium ion concentrations, the biological significance of P12 could only be evaluated in vivo. We transferred mutations in L7.2 and L9.2 into T4 bacteriophage bearing both a complete intron and an in-frame fusion of $l a c Z$ to the second exon of sunY. Splicing efficiency was measured both by $\beta$-galactosidase enzyme activity and by direct determination of the levels of spliced and precursor RNAs by reverse transcription (Fig. 7). We tested the single mutations G131C and C1013G, the double mutations G131C,C132G and G1012C,C1013G, and the respective compensatory double substitutions (to restore base-pairing). L7.2 or L9.2 single mutants and the L9.2 double mutant achieved $<10 \%$ of the wild-type splicing level (Fig. 7B). As expected from the in vitro experiments, the L7.2 double mutant was affected even more severely, yielding no observable spliced product. However, there was substantial restoration of activity when either the single or double mutations were combined to restore the proposed P12 pairing. Combining the double mutations produced a twofold increase (cf. lanes 2-4), whereas the combined single mutations stimulated splicing activity sevenfold (cf. lanes 5-7). The effect of these mutations on production of biologically active sunY-lacZ mRNA was even more dramatic, with none of the individual mutants producing $>1 \%$ of the wild-type enzyme activity (Fig. 7A). Nevertheless, the compensatory double substitutions also restored substantial activity in this assay. 

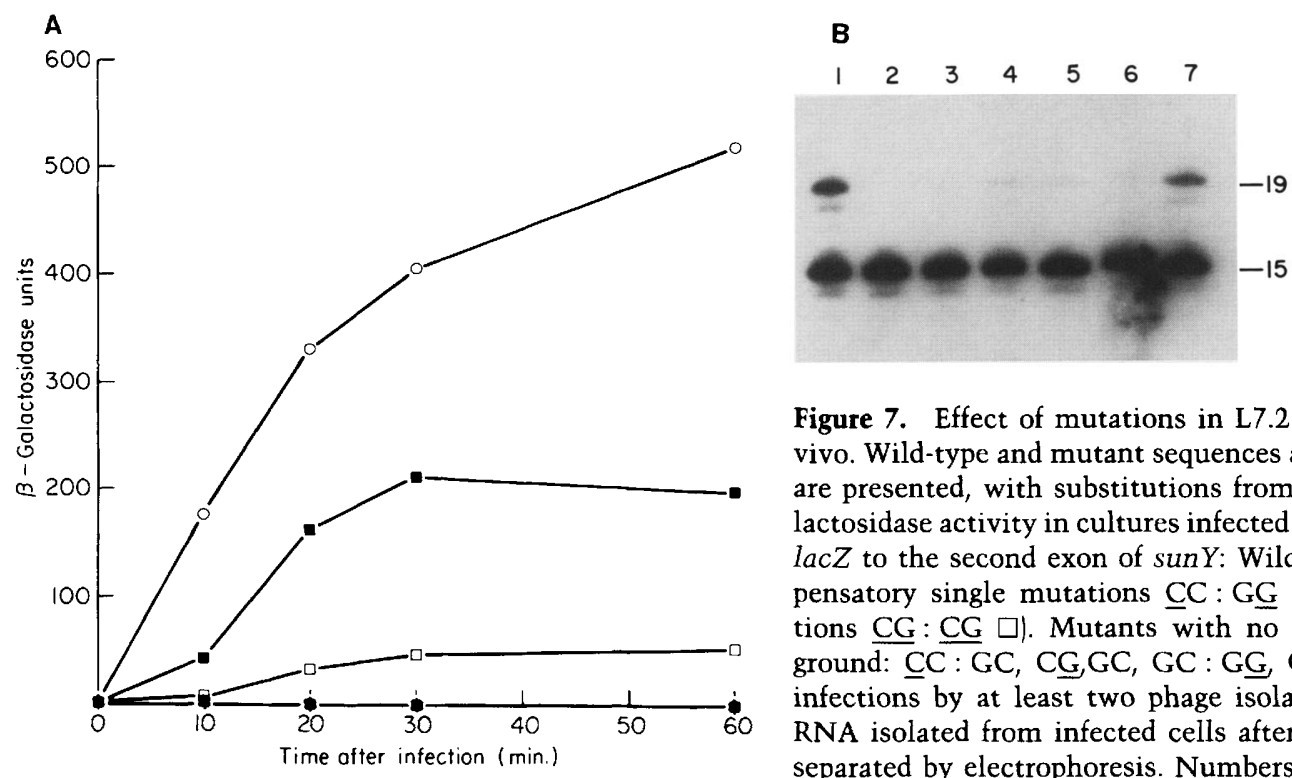

Figure 7. Effect of mutations in L7.2 and L9.2 on splicing activity in vivo. Wild-type and mutant sequences at positions $(131,132: 1012,1013)$ are presented, with substitutions from wild type underlined. $(A) \beta$-Galactosidase activity in cultures infected with $\mathrm{T} 4$ phage bearing a fusion of lacZ to the second exon of sunY: Wild-type introns GC: GC Ol, compensatory single mutations $\underline{C}$ : GG $\square$ ), compensatory double mutations $\mathrm{CG}: \underline{\mathrm{CG}} \square$ ). Mutants with no significant activity above background: $\underline{C}$ : GC, CG, GC, GC: GG $, \mathrm{GC}: \underline{\mathrm{CG}}$. Points are averages of infections by at least two phage isolates. $\langle B\rangle$ Reverse transcription of RNA isolated from infected cells after $9 \mathrm{~min}$ at $37^{\circ} \mathrm{C}$. Reactions were separated by electrophoresis. Numbers at right represent cDNA extensions of the primer (calibrated with a set of sequencing reactions on cloned DNA run in adjacent lanes; data not shown) terminated after 15 residues on presursor RNA templates and after 19 residues on spliced-exon templates. Mutants and percent of wild-type splicing activity: (lane 1) GC: GC (wild type, $100 \%$; fraction spliced, 0.23 ); (lane 2) CG : GC, $0 \%$; (lane 3) GC: CG, 8\%; (lane 4) $\underline{\mathrm{CG}}: \underline{\mathrm{CG}}, 21 \%$; (lane 5 ) $\mathrm{CC}: \mathrm{GC}, 8 \%$; (lane 6) GC : GG, $6 \%$; (lane 7) $\underline{\mathrm{CC}}: \mathrm{GG}, 54 \%$.

\section{A three-dimensional model of the entire sunY ribozyme}

A three-dimensional model of the common core of group I introns based on comparative sequence analysis, nucleotide substitution data, and stereochemical modeling was published recently (Michel and Westhof 1990). Possibly the best way to judge such a model is from its ability to incorporate additional data without the need for extensive revision. In the present case, we checked that when grafting the P7.1, P7.2, P9.1, and P9.2 peripheral components of the sunY intron on the model we had proposed for the core of the ribosomal intron of yeast mitochondria (abbreviated as Sc.LSU), classic base pairs could readily be formed between the L7.2 and L9.2 terminal loops without disrupting any of the previously built tertiary interactions (Fig. 8). That is, the newly described P12 pairing is fully compatible with our previously proposed architecture of group I introns.

We chose to elaborate on the Sc.LSU core model, rather than that of the Tetrahymena intron, because the Sc.LSU and sunY introns belong to the same subgroup (IA) of group I introns. Among other common features, these two introns share 7-bp P9 stems, whose GNRAtype terminal loops have been proposed to interact with consecutive purines in the minor groove of stem P5 (Figs.
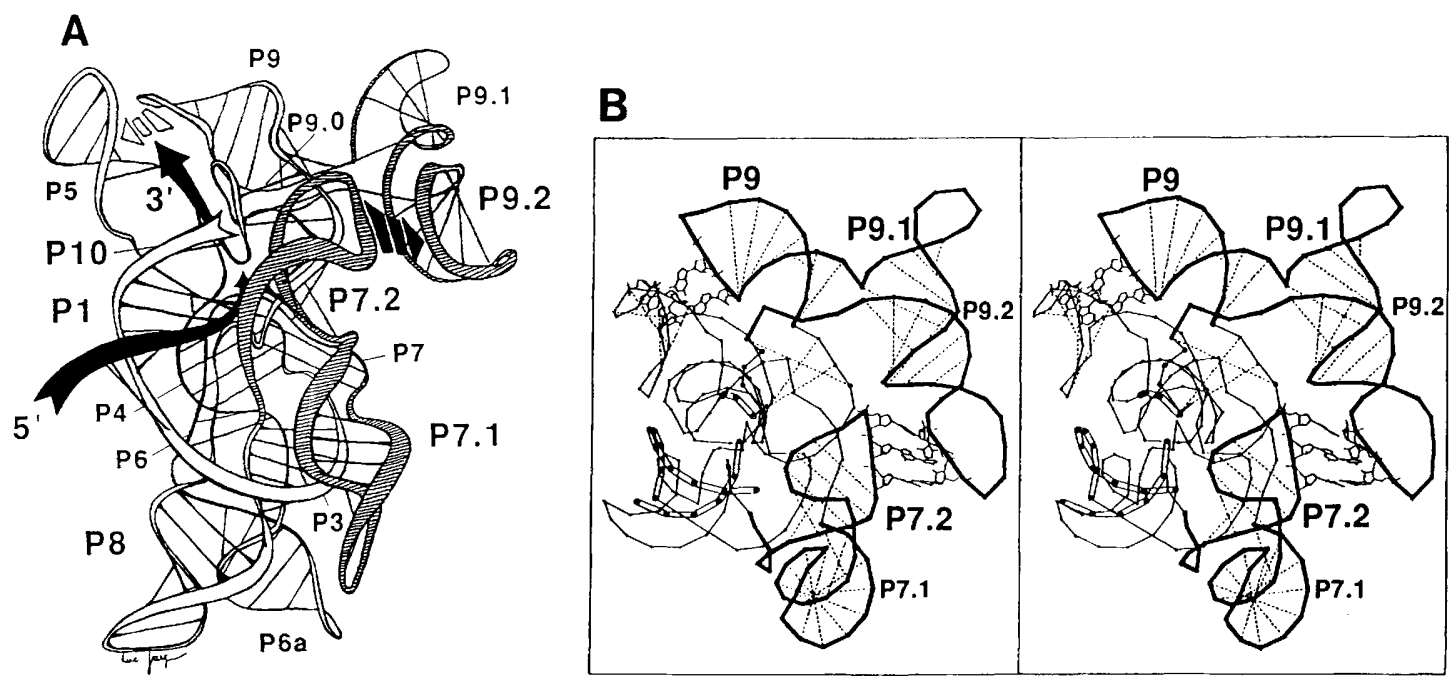

Figure 8. Drawing and stereo views of the sunY intron, with emphasis on the interaction between the P7.2 and P9.2 peripheral domains. $(A)$ The stage just prior to the ligation step (cf. with Fig. 3 in Michel and Westhof 1990). Exons are solid; P7.1, P7.2, P9.1, and P9.2 subdomains are striped. Broken arrows symbolize the L7.2-L9.2 and L9-P5 interactions. $(B)$ Views are from the top of $A$. 
4 and 8; Michel and Westhof 1990). Also, their P9.0 pairings appear to be composite, actually consisting of 3 , rather than 2 bp [Fig. 4; Michel and Westhof 1990 (Appendix); L. Jaeger, E. Westhof, and F. Michel, unpubl.].

The first step in model-building thus consisted of inserting the P9.1 and P9.2 stems of the sunY intron between the previously modeled P9 and P9.0 components of the Sc.LSU intron. The P9.1 helix is adjacent to both P9 and P9.2 and could therefore stack on either of these two helices. However, stacking of P9 and P9.1 would result in the latter helix overlapping with P9.0. On the other hand, coaxial stacking of P9.1 and P9.2 is favorable, owing to the presence of two consecutive guanine residues at the P9.1-P9.2 junction. We chose to orient the P9.1-P9.2 stack with the tip of P9.1 looking toward the L9 loop because (1) in the reverse orientation, the strands entering and leaving the coaxial stack would cross each other, resulting in left-handed stacking of the base pairs at the P9.1-P9.2 junction (for discussion, see Murchie et al. 1989, 1990; Krol et al. 1990); (2) the chosen orientation facilitates insertion of the P9.1b and P9.1c stems (data not shown); (3) the phylogenetically conserved, bulged residue in the $5^{\prime}$ branch of $\mathrm{P} 9.1$ (a $\mathrm{U}$ in the sunY and $t d$ introns, an A in the $n r d B$ intron) can be oriented toward the exterior of the helix, so as to interact with the backbone of P9. The orientation of the P9.1-P9.2 stack about its axis is dictated by the stereochemistry of nucleotides entering and leaving and also by packing contacts of the P9.2 stem with the ribozyme core.

We then inserted the P7.1 and P7.2 stems in between P7 and P3. The orientation of P7.1 (roughly parallel to P3) was dictated ( 1 ) by our choice of minimal perturbation of the core, and (2) by the absence of single-stranded nucleotides between P7 and P7.1. The P7.2 stem was assumed to lie roughly opposite to P7.1, in such a way that $3 \mathrm{bp}$ (two Watson-Crick and one A : G) could be formed between the L7.2 and L9.2 terminal loops. Note that the chosen orientation of P7.2 is compatible with a stereochemically satisfying right-handed loop for the nucleotides at the junction between P7.2 and P3. All but one of the nucleotides separating P7.2 from P3, on one hand, and P7.1 from P7.2, on the other, are conserved in the three bacteriophage T4 introns; and they are therefore likely to play an essential part in giving the P7.1 and P7.2 elements their correct orientation /which could be achieved either through the conserved bases contacting the ribose-phosphate backbones of P7 and P7.1 or by formation of base triples, as might exist between G121 and the G124-C137 base pair). Both the P9-P9.1-P9.2 and P7.1-P7.2 domains could thus fold autonomously into relatively rigid parts which, by interacting together, would specify the final conformation of the entire ribozyme (Fig. 8).

\section{Discussion}

Structural and biological significance of the P12 pairing

In this work we have shown that mutual pairing of the terminal loops of two peripheral components of the sunY intron is required for proper folding of this molecule into an active self-splicing RNA at physiological magnesium concentrations. In contrast to wild-type sunY transcripts, only a fraction of molecules with a severely disrupted $\mathrm{P} 12$ pairing regain activity at $5 \mathrm{mM} \mathrm{MgCl}$ after having been unfolded by purification from denaturing gels and heating in water. On the other hand, the P12 interaction does not seem to be directly involved in catalysis: Although further kinetic characterization of the molecules that succeeded in refolding may perhaps reveal some degree of impairment, we have no evidence so far that this is the case.

This is not the first time that base-pairing between two peripheral, noncore components of a group I intron is shown to be required for full activity: [The P11 pairing of subgroup IAl introns (Michel and Westhof 1990; the sunY intron has been classified as IA2) was shown recently to be involved in the formation and maintenance of an active intron structure in the case of yeast mitochondrial preRNA (Jaeger et al. 1991).] Nor is this the first instance of trans-activation of the central core of a group I intron by a separately transcribed peripheral domain, for it was reported by van der Horst et al. (1991) that incubation of the domain distal to the $\mathrm{P} 5$ pairing of the Tetrahymena ribosomal intron with the rest of the molecule allows activity to be regained at a low magnesium concentration. However, no group I intron is known with a separately encoded P5 extension domain, whereas some 800 nucleotides separate the core of the sunY intron from the P9.2 hairpin and attached 3' splice site.

The best analogy to the sunY type of organization is to be sought in the other group of catalytic introns. The 3' splice site of group II introns is immediately preceded by two typically small domains (V and VI) that are often separated from the rest of the intron by a long reading frame or may even be part of a separate transcript originating from a distant genomic location /Chapdelaine and Bonen 1991; Goldschmidt-Clermont et al. 1991; Knoop et al. 1991; Wissinger et al. 1991). Although all interactions shown so far to participate in selection of a 5 ' splice site involve domain I (Jacquier and Michel 1990), the presence of domain $\mathrm{V}$ is somehow necessary to trigger cleavage at the $5^{\prime}$ junction (Jarrell et al. 1988; the normal $2^{\prime} \mathrm{OH}$ attacking group actually resides within domain VI, but is not essential because splicing can also proceed by hydrolysis at the intron-5' exon junction). Such a device has the obvious advantage of preventing premature cleavage at the $5^{\prime}$ splice site (and the ensuing dissociation of the $5^{\prime}$ exon) or mis-splicing to surrogate $3^{\prime}$ splice sites.

In the same manner, we have shown that formation of a fully active complex /under low magnesium conditions) between the core and $5^{\prime}$ splice site of the sunY intron requires the formation of the 9.2 terminal loop, whose remote location, only a few nucleotides upstream of the authentic splice junction, readily explains why proximal splicing events cannot be detected. It is likely that these conclusions also apply in vivo, because disruption and restoration of base-pairing between L7.2 and 
L9.2 have the expected large effects on splicing (Fig. 7; mutations in the P9.2 stem-and-loop structure, as well as in the L7.2 loop, of the closely related $t d$ intron were already known to inactivate splicing in vivo; Belfort et al. 1987).

The molecular interactions responsible for efficient recognition of group II domains V and VI remain essentially unidentified. Although some of the nucleotides immediately $5^{\prime}$ of domain $\mathrm{V}$ can usually base-pair with the ones immediately $3^{\prime}$ of the rest of the ribozyme core, these sequences proved dispensable when trans-splicing was assayed in vitro (Jarrell et al. 1988). This latter point is, again, reminiscent of the situation in the sunY system, where the $5^{\prime}$ and $3^{\prime}$ extremities of the intron open reading frame display extensive complementarity (Fig. 4), yet the resulting P9.1a and P9.1c pairings are not required in vitro, whether in cis- or trans-splicing situations (note, however, that none of our experiments rule out the possibility that formation of P9.1 is actually rate limiting for splicing).

In contrast with group II, however, several of the essential base-base interactions that hold together the $3^{\prime}$ terminal domain and ribozyme core of the sunY intron have been identified. Consistent with our modeling of the entire molecule (Fig. 8), we now propose that some of these interactions (the P12 pairing and, possibly, the P9.0 composite stem) cooperate with the L9-P5 postulated contact (Michel and Westhof 1990) to drive the core into an active conformation. An alternative interpretation would be that some stretches of nucleotides $3^{\prime}$ of the core happen to somehow compete with the $5^{\prime}$ splice site for access to a correctly folded core, thus preventing $5^{\prime}$ cleavage in truncated transcripts. We regard the latter hypothesis as unlikely because all incomplete sunY transcripts, whether truncated just at the end of stem P9, far away from it, or lacking all sequences in between $\mathrm{P} 9$ and the authentic 3 ' splice junction, display essentially the same degree of dependence on magnesium (Fig. 1).

Finally, the fact that P12 is ascribed an essential role in locking the core into what is likely to be its final active state does not imply that the P7.2 and P9.2 stem-andloop structures have equivalent functions. We observed a double substitution in the L7.2 loop to lead to significantly greater impairment of refolding (Fig. 5) and splicing activity in vivo (Fig. 7) than the corresponding alteration in the L9.2 loop. Also, replacement of the P7.1 and P7.2 stems and loops by a short linker was found to result in a severely disabled ribozyme compared with the starting molecule, despite the fact that the latter already lacked both P9.1 and P9.2 (Doudna and Szostak 1989). Both of these observations suggest that the P7.1-P7.2 domain is associated more intimately with core components than P9.2.

\section{Comparison with other group I introns}

The evolutionarily conserved core common to all group I introns comprises only about 120 nucleotides; however, the smallest known group I intron is 204 nucleotides in length (Kuhsel et al. 1990). This discrepancy has led to persistent efforts to create smaller self-splicing molecules, as might be useful, for instance, for structural studies. Unfortunately, deletion of more than one of the peripheral structural domains of natural group I introns invariably leads to molecules that are either totally inactive or require very high ion concentrations for activity (e.g., Doudna and Szostak 1989; Joyce et al. 1989). It was therefore generally assumed that noncore components of group I introns would be involved in enabling the catalytic core to achieve and retain an active conformation. Recent research on the significance of peripheral structures in three different subgroups of self-splicing introns [IA2 (this work); IA1 (Jaeger et al. 1991); and the Tetrahymena subgroup (Celander and Cech 1991)] illustrates the diversity of solutions that have been invented in the course of evolution to the problem of correctly folding group I intron transcripts.

Not all group I introns are self-splicing, however, and the excision of a number of them has been shown to depend on protein cofactors, which may or may not be encoded within the intron itself (for review, see Cech 1990). Essentially nothing is known of the mode of action of these proteins, but it is tempting to speculate that they will substitute for peripheral RNA-RNA interactions in ensuring that the core gets correctly folded. In fact, some of the introns known from genetic analyses to associate with proteins in vivo (e.g., introns Sc.OX1,4 and Sc.COB, 4 from yeast) are clearly defective for some semiconserved core interactions, such as the putative L9-P5 pairing (Michel and Westhof 1990).

Furthermore, one might speculate that in some of the introns whose core is separated from the $3^{\prime}$ splice junction by a reading frame, activation of that core for distal splicing could not be ensured by some RNA-RNA interaction, as in the sunY intron; rather, it would depend on the protein product of the reading frame. The assumption [as is strongly suggested by the location of potential proximal splice sites (Séraphin 1988; Michel and Westhof 1990)] that expression of these proteins rests on some occasional proximal splicing event putting the intron reading frame in phase with the $5^{\prime}$ exon, would lead to a model in which the intron-encoded protein, by favoring distal over proximal splicing, would participate in the inactivation of its own coding sequence and thus selfregulate. The latter statement is the central assumption of the "maturase" model, which, based on genetic arguments, was proposed by Lazowska et al. (1980) to account for splicing of protein-encoding yeast mitochondrial introns.

\section{Materials and methods}

DNA constructs

The AccI-XbaI fragment of bacteriophage T4 DNA, extending from positions 2747 to 4040 in the sequence of Tomaschewski and Rüger (1987), includes 26 nucleotides of exon $5^{\prime}$ to the sunY intron, the entire intron, as well as the first 238 nucleotides of the 3 ' exon. After filling in the AccI site by the Klenow enzyme, this fragment was ligated to the HincII and $\mathrm{XbaI}$ sites of plasmid pGEM-3 (Promega Biotec) and then transferred (by PstI-EcoRI 
digestion) into plasmid pTZ19U (U.S. Biochemical), eventually resulting in plasmid pSYAX. Site-directed mutagenesis of plasmid pSYAX by the method of Kunkel et al. (1987) resulted in plasmid pSYCl, which lacks intron nucleotides 262-973, and plasmid pSYC3 (identical to pSYCl, except for intron mutations $A 177 G$ and $U 1032 \mathrm{C}$ in the P9.0 pairing). Nucleotide substitutions in the L7.2 and L9.2 loops were introduced by sitedirected mutagenesis of pSYC3 and pSYAX. pSYK15 was obtained by cloning into the Nsp7524I (intron position 189) and SmaI sites of pSYC1, a cassette consisting of the following oligonucleotides: 5'-CAGTTAACACATCGATGAAGTGAACTCGTTATTCA-3' and 5'-TGAATAACGAGTTCACTTCATCGATGTGTTAACTGCATG-3'. All constructs were verified by sequencing the entire intron and neighboring exon sequences.

pMEEl contains the same sunY insert as pMAXl (Xu and Shub 1989\}, except that L9.1 was shortened to 11 bp (Fig. 2) by Bal 31 treatment. The sunY fragment and phage $\mathrm{T} 3$ promoter were removed by EcoRI and partial PvuII digestion and inserted into pNC85 (Zeeh and Shub 1991) cut with EcoRI and EcoRV. The resultant plasmid has a unique PvuII site between P9 and P9.1. Deletions extending toward the $3^{\prime}$ end of the intron were obtained by cutting pMEEl with PvuII and treating with Bal 31 nuclease (slow form, International Biotechnologies, Inc.) Reactions were stopped by adding $50 \mathrm{~mm}$ EDTA, heating at $65^{\circ} \mathrm{C}$ for $15 \mathrm{~min}$, and extracting with phenol. After cutting with EcoRI and separation by electrophoresis on an agarose gel, the band of $\sim 0.3 \mathrm{~kb}$ (containing the $3^{\prime}$ end of the intron) was isolated and ligated to the 2.5-kb EcoRI-PvuII fragment of untreated pMEE1. Plasmids from transformants were screened for the absence of a PvuII site, and the mutations were determined by DNA sequencing. Splicing ability was determined by in vitro transcription of DNA truncated with EcoRI. Incubation with phage T3 polymerase was carried out at $37^{\circ} \mathrm{C}$ for $60 \mathrm{~min}$ in $40 \mathrm{~mm}$ Tris-Cl (pH 8.0), $50 \mathrm{~mm} \mathrm{NaCl}, 8 \mathrm{~mm} \mathrm{MgCl}_{2}, 30 \mathrm{~mm}$ DTT, 2 mM spermidine, $1 \mathrm{U} / \mu \mathrm{l}$ of RNasin (Promega), $400 \mu \mathrm{M}$ each ATP, CTP, UTP, and $20 \mu \mathrm{M}$ GTP, and $20 \mathrm{Ci} / \mathrm{mmole}$ of $\left[\alpha^{-32} \mathrm{P}\right] \mathrm{GTP}$.

The $5^{\prime}$ exon-core transcript used in the bimolecular experiment presented in Figure 3B was generated from a derivative of plasmid pTZ19U/T4AS that carries intron mutations A177G, U210G, and U216C (mutant 4 in Fig. 4 of Michel et al. 1990). Plasmids used to generate RNAs carrying part of the distal $3^{\prime}$ junction of the sunY intron were pSS1 and pSS2, generated by cloning the HindIII(256)-RsaI(1094) fragments of pSYC1 and pSYC3, respectively, into the HindIII and SmaI sites of pTZ19U; pSS3, generated by cloning the HindIII(256)ClaI(1030) fragment of pSYC3 into the HindIII and AccI sites of pTZ19U; pSS4, obtained by cloning the ClaI(1030)-EcoRI fragment of pSYC3 into the AccI and EcoRI sites of pTZ19U; and pSK15, obtained by cloning into the SphI and EcoRI sites of pTZ19U the Nsp7524I|189)-EcoRI fragment of pSYK15.

\section{RNA synthesis and purification}

Linearized plasmid DNA $(5.0 \mu \mathrm{g})$ was incubated for $3 \mathrm{hr}$ at $37^{\circ} \mathrm{C}$ with T7 RNA polymerase in $10 \mathrm{~mm} \mathrm{NaCl}, 40 \mathrm{~mm}$ Tris- $\mathrm{HCl} / \mathrm{pH}$ 7.5), $6 \mathrm{mM} \mathrm{MgCl}_{2}, 10 \mathrm{~mm}$ dithiothreitol, $2 \mathrm{~mm}$ spermidine, $2 \mathrm{~mm}$ of each ribonucleoside triphosphate (except UTP, whose concentration was $1 \mathrm{~mm}$ ), 20 units of RNasin (Promega Biotec), and $10 \mu \mathrm{Ci}$ of $\left[\alpha^{-32} \mathrm{P}\right] \mathrm{UTP}(800 \mathrm{Ci} / \mathrm{mmole})$. No splicing was detected during transcription under these conditions. Transcripts were purified by electrophoresis on a $4 \%$ acrylamide $-8 \mathrm{M}$ urea gel, followed by elution overnight in $0.2 \mathrm{M}$ Tris- $\mathrm{HCl}(\mathrm{pH} 7.5), 0.3 \mathrm{M}$ $\mathrm{NaCl}$, and $2 \%$ SDS. After two phenol extractions, the supernatant was ethanol precipitated and the pellet was rinsed twice with $70 \%$ ethanol before drying and resuspension in water.
Splicing experiments and quantitation of ${ }^{32}$ P-labeled RNA species

Unless otherwise stated in the figure legends, all RNA samples for monomolecular splicing experiments were heated at $80^{\circ} \mathrm{C}$ in water and quick cooled to $45^{\circ} \mathrm{C}$ before addition of $5 \times$ concentrated splicing buffer $\left[50 \mathrm{~mm}\right.$ Tris- $\mathrm{HCl}\left(\mathrm{pH} 7.5\right.$ at $\left.25^{\circ} \mathrm{C}\right), 50 \mathrm{~mm}$ $\mathrm{NH}_{4} \mathrm{Cl}, 0.02 \%$ SDS, with variable amounts of $\mathrm{MgCl}_{2}$ ] and slow cooling $\left(-0.8^{\circ} \mathrm{C} / \mathrm{min}\right)$ to $37^{\circ} \mathrm{C}$ or $30^{\circ} \mathrm{C}$. The concentration of precursor RNA (estimated from radioactive counts) was routinely set at $30 \mathrm{nM}$. Reactions were started by addition of GTP to a final concentration of $1 \mathrm{mM}$ and stopped by addition of loading buffer $\left[50 \%(\mathrm{wt} / \mathrm{vol})\right.$ ureal and $\mathrm{Na}_{2}$-EDTA to a final concentration of $40 \mathrm{~nm}$.

Reaction samples were analyzed by electrophoresis on $5 \%$ acrylamide- $8 \mathrm{M}$ urea gels. Bands on autoradiographs were quantitated either by optical scanning of varied exposures or with the help of the prototype Scintillating Optical Fiber Imager of Leblanc et al. (1988; results were checked to be consistent with the two methods).

Splicing in vivo was determined by a variation of the method of Pikielny and Rosbash (1985). Reverse transcription of $5 \mu \mathrm{g}$ of crude RNA was performed at $37^{\circ} \mathrm{C}$ for 10 min with 0.65 units of AMV reverse transcriptase (Life Sciences); $60 \mu \mathrm{M}$ each of dATP, $\mathrm{dCTP}$, and dTTP; and $169 \mu \mathrm{M}$ ddGTP. An oligonucleotide complementary to the 3 ' exon beginning 10 nucleotides from the splice site (coordinates 3836-3860 of Tomaschewski and Rüger 1987) was ${ }^{32} \mathrm{P}$-end-labeled with polynucleotide kinase and used as primer. Under these conditions, synthesis terminates at the first template cytosine, after 15 nucleotides on the precursor RNA and 19 nucleotides on the spliced exon RNA, respectively. The cDNA species were separated by electrophoresis on an $8 \%$ acrylamide- $8 \mathrm{M}$ urea gel, and quantitated (after drying) on a Betascope 603 blot analyzer (Betagen Corp.).

\section{Bacteriophage experiments}

Growth and infection of Escherichia coli $\mathrm{B}_{\mathrm{E}}\left(\right.$ at $\left.37^{\circ} \mathrm{C}\right)$, extraction of RNA, and $\beta$-galactosidase assays were as described previously (Gott et al. 1988). Mutations in L7.2 and L9.2 in pSYAX were transferred into $\mathrm{T} 4$ phage by recombination, using the mutagenic oligonucleotides as plaque hybridization probes (Gott et al. 1988). After introducing L7.2 mutations, compensatory L9.2 mutations were added. To assure retention of the L7.2 mutations in recipient phage, the $5^{\prime}$ ends of intron sequences were deleted from the donor plasmids with Nsp7524I. Recipient phage carried an in-frame lac $Z$ fusion inserted at the $X b a I$ site 238 nucleotides into the $3^{\prime}$ exon, as well as the compensating deletion $\mathrm{Sa} \Delta 9$ (Zeeh 1989).

\section{Computer modeling}

Molecular modeling was performed as described in Michel and Westhof (1990).

\section{Note}

After this work was completed, we learned of the study of Heuer et al. (1991), who determined the accessibility of truncated forms of the sunY and $t d$ introns to Fe(II)-EDTA. Most portions of the intron predicted by our model of the entire sunY molecule to be inaccessible to solvent are protected from Fe(II)-EDTA cleavage according to the experiments of these investigators. On the other hand, both strands of the $\mathrm{P} 7$ pairing are reported to be shielded, whereas they are not protected in our current 
model. This discrepancy could easily be resolved by moving the P7.2 and P9.2 stems slightly closer to the core.

\section{Acknowledgments}

We thank Annie Hoeft (Institut de Biologie Moléculaire et Cellulaire du CNRS, Strasbourg) and Denise Menay (Centre de Génétique Moléculaire du CNRS, Gif-sur-Yvette) for synthesizing DNA oligonucleotides, Hervé Tricoire for access to the Scintillating Optical Fiber Imager, and Sean Eddy and Larry Gold for providing an unpublished protocol and oligonucleotide primer for reverse transcription of in vivo RNA. R.K. and F.T. were rotation students from the D.E.A. de Génétique Cellulaire et Moléculaire at Université Paris 6. Work in the laboratory of D.A.S. was supported by grant GM37746 from the National Institutes of Health.

The publication costs of this article were defrayed in part by payment of page charges. This article must therefore be hereby marked "advertisement" in accordance with 18 USC section 1734 solely to indicate this fact.

\section{References}

Been, M.D. and A.T. Perrotta. 1991. Group I intron self-splicing with adenosine: Evidence for a single nucleoside-binding site. Science 252: 434-437.

Belfort, M., P.S. Chandry, and J. Pedersen-Lane. 1987. Genetic delineation of functional components of the group I intron in the phage T4 $t d$ gene. Cold Spring Harbor Symp. Quant. Biol. 52: 181-192.

Burke, J.M. 1989. Selection of the $3^{\prime}$ splice site in group I introns. FEBS Lett. 250: 129-133.

Burke, J.M., J.S. Esherick, W.R. Burfeind, and J.L. King. 1990. A $3^{\prime}$ splice site-binding sequence in the catalytic core of a group I intron. Nature 344: 80-82.

Cech, T.R. 1988. Conserved sequences and structures of group I introns: Building an active site for RNA catalysis-A review. Gene 73: 259-271.

- 1990. Self-splicing of group I introns. Annu. Rev. Biochem. 59: 543-568.

Celander, D.W. and T.R. Cech. 1991. Visualizing the higher order folding of a catalytic RNA molecule. Science 251: 401407.

Chapdelaine, Y. and L. Bonen. 1991. The wheat mitochondrial gene for subunit I of the NADH dehydrogenase complex: A trans-splicing model for this gene-in-pieces. Cell 65: 465472.

Davies, R.W., R.B. Waring, J.A. Ray, T.A. Brown, and C. Scazzocchio. 1982. Making ends meet: A model for RNA splicing in fungal mitochondria. Nature 300: 719-724.

Doudna, J.A. and J.W. Szostak. 1989. Miniribozymes, small derivatives of the sun $Y$ intron, are catalytically active. Mol. Cell. Biol. 9: 5480-5483.

Goldschmidt-Clermont, M., Y. Choquet, J. Girard-Bascou, F. Michel, M. Shirmer-Rahire, and J.D. Rochaix. 1991. A small chloroplast RNA may be required for trans-splicing in Chlamydomonas reinhardtii. Cell 65: 135-143.

Gott, J.M., A. Zeeh, D. Bell-Pedersen, K. Ehrenman, M. Belfort, and D.A. Shub. 1988. Genes within genes: Independent expression of phage T4 intron ORFs and the genes in which they reside. Genes \& Dev. 2: 1791-1799.

Hensgens, L.A.M., L. Bonen, M. de Haan, G. van der Horst, and L.A. Grivell. 1983. Two intron sequences in yeast mitochondrial COX1 gene: Homology among URF-containing introns and strain-dependent variation in flanking exons. Cell
32: 379-389.

Heuer, T.S., R.S. Chandry, M. Belfort, D.W. Celander, and T.R. Cech. 1991. Folding of group I introns from bacteriophage T4 involves internalization of the catalytic core. Proc. Natl. Acad. Sci. 88: 11105-11109.

Inoue, T., F.X. Sullivan, and T.R. Cech. 1986. New reactions of the ribosomal RNA precursor of Tetrahymena and the mechanism of self-splicing. J. Mol. Biol. 189: 143-165.

Jacquier, A. and F. Michel. 1990. Base-pairing interactions involving the $5^{\prime}$ and $3^{\prime}$-terminal nucleotides of group II selfsplicing introns. I. Mol. Biol. 213: 437-447.

Jaeger, L., E. Westhof, and F. Michel. 1991. Function of Pl1, a tertiary base-pairing in self-splicing introns of subgroup IA. $/$. Mol. Biol. 221: 1153-1164.

Jarrell, K.A., R.C. Dietrich, and P.S. Perlman. 1988. Group II intron domain 5 facilitates a trans-splicing reaction. Mol. Cell. Biol. 8: 2361-2366.

Joyce, G.F., G. van der Horst, and T. Inoue. 1989. Catalytic activity is retained in the Tetrahymena group I intron despite removal of the large extension of element P5. Nucleic Acids Res. 17: 7879-7889.

Knoop, V., W. Schuster, B. Wissinger, and A. Brennicke. 1991. Trans-splicing integrates an exon of 22 nucleotides into the nad5 mRNA in higher plant mitochondria. EMBO $I$. 10: 3483-3493.

Krol, A., E. Westhof, M. Bach, R. Luhrmann, J.-P. Ebel, and P. Carbon. 1990. Solution structure of human Ul snRNA. Derivation of a possible three-dimensional model. Nucleic Acids Res. 18: 3803-3811.

Kuhsel, M.G., R. Strickland, and J.D. Palmer. 1990. An ancient group I intron shared by eubacteria and chloroplasts. Science 250: 1570-1573.

Kunkel, T.A., J.D. Roberts, and R.A. Zakour. 1987. Rapid and efficient site-directed mutagenesis without phenotype selection. Methods Enzymol. 154: 367-382.

Lazowska, J., C. Jacq, and P.P. Slonimski. 1980. Sequence of introns and flanking exons in wild-type and box 3 mutants of cytochrome $b$ reveals an interlaced splicing protein coded by an intron. Cell 22: 333-348.

Leblanc, M., C. Raymond, H. Tricoire, and L. Valentin. 1988. SOFI: A scintillating optical fiber imager. Nucl. Instrum. Methods 273: 583-588.

Michel, F. and E. Westhof. 1990. Modelling of the three-dimensional architecture of group I catalytic introns based on comparative sequence analysis. J. Mol. Biol. 216: 585-610.

Michel, F., A. Jacquier, and B. Dujon. 1982. Comparison of fungal mitochondrial introns reveals extensive homologies in RNA secondary structure. Biochimie 64: 867-881.

Michel, F., M. Hanna, R. Green, D.P. Bartel, and J.W. Szostak. 1989. The guanosine binding site of the Tetrahymena ribozyme. Nature 342: 391-395.

Michel, F., P. Netter, M.-Q. Xu, and D.A. Shub. 1990. Mechanism of $3^{\prime}$ splice site selection by the catalytic core of the sunY intron of bacteriophage T4: The role of a novel basepairing interaction in group I introns. Genes \& Dev. 4: 777788.

Murchie, A.I.H., R.M. Clegg, E. von Kitzing, D.R. Duckett, S. Diekmann, and D.M.J. Lilley. 1989. Fluorescence energy transfer shows that the four-way DNA junction is a righthanded cross of antiparallel molecules. Nature 341: 763766.

Murchie, A.I.H., W.A. Carter, J. Portugal, and D.M.J. Lilley. 1990. The tertiary structure of the four-way DNA junction affords protection against DNase I cleavage. Nucleic Acids Res. 18: 2599-2606.

Partono, S. and A.S. Lewin. 1990. Splicing of COB intron 5 re- 
quires pairing between the internal guide sequence and both flanking exons. Proc. Natl. Acad. Sci. 87: 8192-8196.

Pikielny, C.W. and M. Rosbash. 1985. mRNA splicing efficiency in yeast and the contribution of nonconserved sequences. Cell 41: 119-126.

Séraphin, B. 1988. "Etude de l'unité de transcription mitochondriale oxi3/oli2 chez la levure Saccharomyces cerevisiae". Ph.D. thesis. Université Paris 6, Paris, France.

Shub, D.A., J.M. Gott, M.-Q. Xu, B.F. Lang, F. Michel, J. Tomaschewski, Petersen-Lane, and M. Belfort. 1988. Structural conservation among three homologous introns of phage T4 and the group I introns of eukaryotes. Proc. Natl. Acad. Sci. 85: 1151-1155.

Suh, E.R. and R.B. Waring. 1990. Base pairing between the 3' exon and an internal guide sequence increases splice site specificity in the Tetrahymena self-splicing rRNA intron. Mol. Cell. Biol. 10: 2960-2965.

Tomaschewski, J. and W. Rüger. 1987. Nucleotide sequence and primary structures of gene products coded for by the T4 genome between map positions 48.266 and $39.166 \mathrm{~kb}$. Nucleic Acids Res. 15: 3632-3633.

van der Horst, G., A. Christian, and T. Inoue. 1991. Reconstitution of a group I intron self-splicing reaction with an activator RNA. Proc. Natl. Acad. Sci. 88: 184-188.

Wissinger, B., W. Schuster, and A. Brennicke. 1991. Trans-splicing in Oenothera mitochondria: nad $1 \mathrm{mRNAs}$ are edited in exon and trans-splicing group II intron sequences. Cell 65: 473-482.

Xu, M.-Q. and D.A. Shub. 1989. The catalytic core of the sunY intron of bacteriophage T4. Gene 82: 77-82.

Zeeh, A. 1989. "RNA and protein processing in bacteriophage T4." Ph.D. thesis. State University of New York at Albany, Albany, New York.

Zeeh, A. and D.A. Shub. 1991. The product of the split sunY gene of bacteriophage T4 is a processed protein. J. Bacteriol. 173: 6980-6985. 


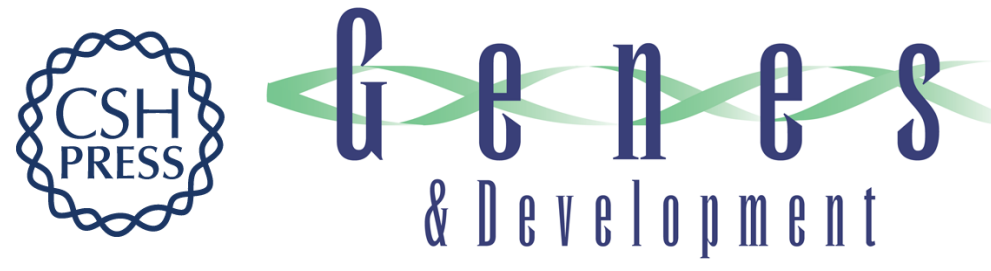

\section{Activation of the catalytic core of a group I intron by a remote $3^{\prime}$ splice junction.}

F Michel, L Jaeger, E Westhof, et al.

Genes Dev. 1992, 6:

Access the most recent version at doi:10.1101/gad.6.8.1373

References This article cites 40 articles, 14 of which can be accessed free at:

http://genesdev.cshlp.org/content/6/8/1373.full.html\#ref-list-1

License

Email Alerting

Service

Receive free email alerts when new articles cite this article - sign up in the box at the top right corner of the article or click here.

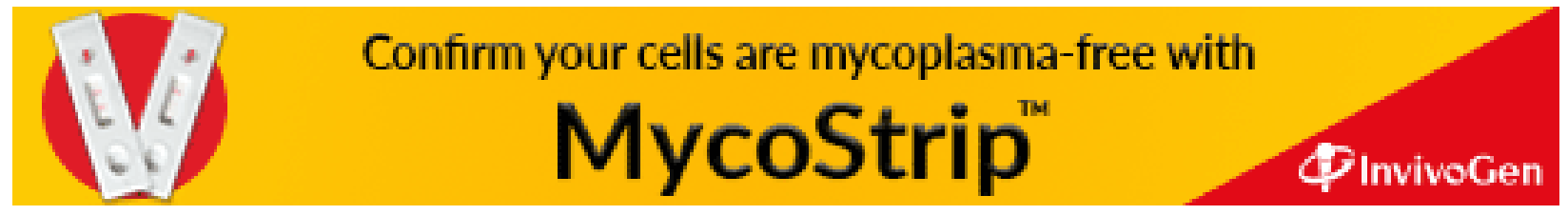

